\title{
Use of Risk Analysis for Water Security Assessment
}

\author{
Samah Jabari ${ }^{1}$, Isam Shahrour ${ }^{1}$, Jamal khatabi ${ }^{1}$ \\ ${ }^{1}$ Laboratoire de Génie Civil et géo-Environnement, Université de Lille, 5900 Lille, France
}

\begin{abstract}
This paper presents analysis of water security using risk analysis. It contributes to an enhanced understanding of the water security issue through creating indicators and their use in the determination of the water security level. The paper presents first the methodology followed in this research, which includes three steps: identification of water risk drivers, the determination of their severity and likelihood and finally the calculation of the water security score. The paper presents the first step of the application of this methodology to Palestinian territory through the identification of the drivers of the water risk and the levels of both the severity and likelihood to be used in future water security assessment.
\end{abstract}

\section{Introduction}

Many countries around the world face severe water crisis [1]. For these countries, the water security constitutes a critical issue ([2] \& [3]). The water security concept is large combines different factors, which are related to political, social, financial, infrastructural, environmental, managerial and natural disasters issues ([4] \& [5]). This issue is becoming critical, because of rapid population as well as lack of investments in, conflicts and climate change ([5], [6], [7] and [8]). Therefore, it is necessary to conduct research to assess water security with metric expression and numerical dimensions ([7] \& [9]). [2] Pointed out that quantifying water security results in an increase of our understanding of this critical issue, to establish the needs in this area and to evaluate strategies concerning water security.

Recently the risk approach was used in water security assessment [10]. It allows to identify uncertainties in this field and to characterize these risks quantitatively and qualitatively [5]. Nowadays water managers are more interested by the water risks than by maximizing the water resources performances [8]. Mason and Calow discuss the importance of risk in water security by using a set of indicators [9]. Grey and his collages identified the water security as the society acceptable water related risks [1]. The Institute for Water, Environment \& Health of the United Nations University used the concept of water related risks in the definition of water security [8]. Lautze and Manthrithilake proposed water security indicators including risk management [2]. Garrick and Hall in their publication "Water Security and Society: Risks, Metrics, and Pathways" pointed out that the use of the risk concept in water security allows to provide robust diagnoses tools for the evaluation of the water security as well as its drivers [13]. At the same context other 
literature indicates that risk-based approach of the water insecurity improves the resilience of the water system [11].

\section{Methodology}

Figure 1 shows the methodology followed in this research for the use of risk assessment in water security analysis. It includes three main steps:

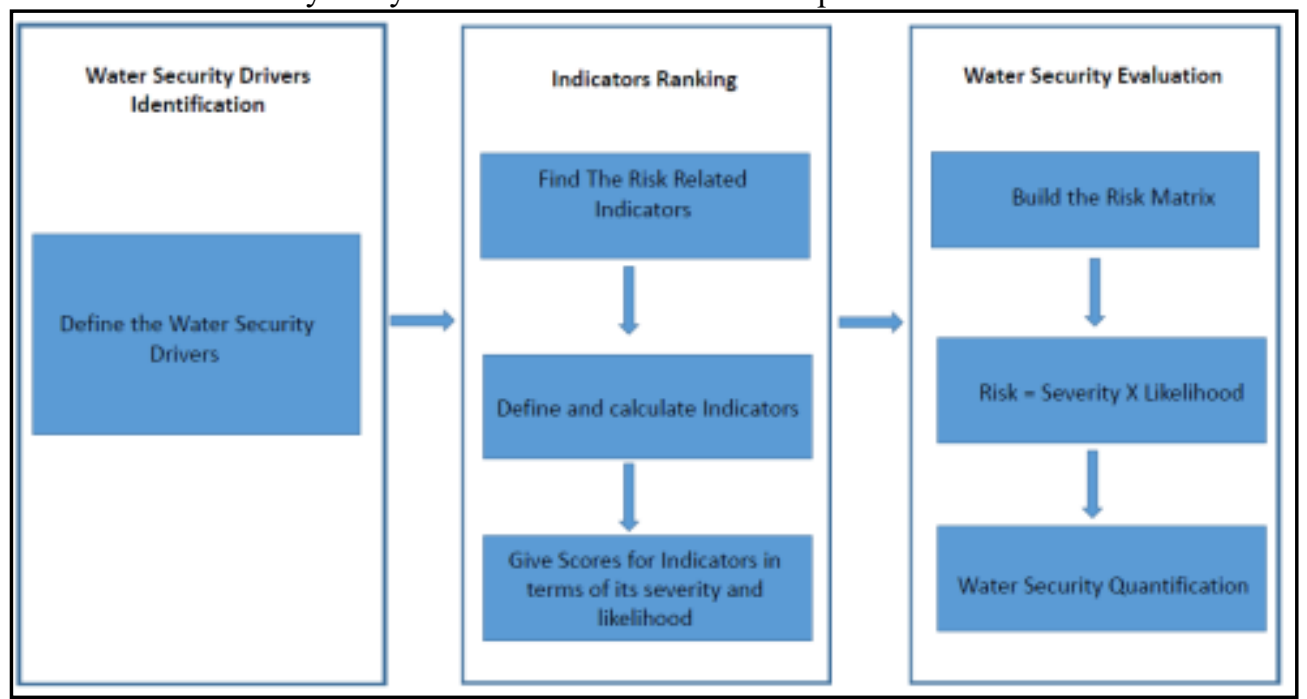

Fig. 1. Water Security Evaluation Framework

Step 1: Identification of water security drivers:

This step concerns identification of the factors (drivers) affecting water security. This step is complex, because it requires a deep and comprehensive understanding the multitude of issues related to the water security, which were discussed previously in this paper. It concerns technical, environmental, social, economic and political issues. Each indicator should be clearly identified as well as its determination and impact on water security.

Step 2: Indicators ranking:

Indicators ranking constitutes a complex and sensitive issue. It has a great impact on the analysis of water security and on priorities and strategies to be implemented in the water security plans. The use of the risk assessment approach requires the determination of the severity score and the likelihood for each driver. The former indicates the amplitude of the impact of the indicator on water security, while the latter provides an estimation of the probability of occurrence of this driver. The determination of both the score and likelihood should be based on literature review, experts consulting and benchmarking.

Step 3: Water security evaluation:

Water security is evaluated from the drivers' severity score and likelihood according to the following expression:

$$
\text { R.S }=S . S \times L . S
$$

Where;

R.S: Risk Score (from 1 to 25 )

S.S: Severity Score (from 1 to 5) 


\section{Application to Palestinian Territory}

The Palestinian territory faces a severe state of water insecurity ([14] \& [15]), because it is subjected to an increasing pressure related to climate conditions, urbanization, conflict, lack of investment and modernization in the water management [16].

Both extensive literature review and discussion with experts allowed the identification of the drivers of the water security as well as their scores and likelihoods. Drivers of the water security were classified in three categories: Water resources availability, quality of water services and governance. Table 1 summarizes the indicators associated to each category of drivers.

Water resources drivers include three indicators: Water resources availability, Annual precipitation and ratio of treated waste water. The quality of water services for the population is governed by three indicators: Water coverage, Water losses and Continuity of the water supply. Finally, for the water governance the following three indicators were identified: Roles and responsibilities, access to data and information and Stakeholders' engagement.

Discussions are under progress for the determination for each indicator both the severity score and likelihood score using for each of them the levels summarized in table 2 . The result of calculation of the risk score from Eq. 1 and the risk matrix expressed in table 3 , then it will be used according to table 4 for the evaluation of the water security score.

The risk matrix which shown in table 3 was used to calculate the risk score for each indicator. The arithmetic mean for summation of indicator scores in a certain category will give the water security driver risk score. This score will rate the risk in to low, medium, high, and extreme level. Then risks scores and levels translated to water security scores and levels as shown in the suggesting system at table 4.

Table 1. Water Security Drivers and Associated Indicators for Palestine Territory

\begin{tabular}{|c|l|}
\hline \multicolumn{1}{|c|}{ Security Driver } & \multicolumn{1}{c|}{ Indicators } \\
\hline \multirow{4}{*}{ Water resources } & Water resources availability \\
\cline { 2 - 3 } Quality of water Services & Annual Precipitation \\
\cline { 2 - 3 } & Ratio of Treated Waste Water \\
\cline { 2 - 2 } & Water coverage \\
\cline { 2 - 2 } & Continuity of supply \\
\hline \multirow{4}{*}{ Water Governance } & Clear Roles and Responsibilities \\
\cline { 2 - 2 } & Access to Data and Information \\
\cline { 2 - 2 } & Stakeholders' Engagement \\
\hline
\end{tabular}


Table 2. Severity and Likelihood Ranking System

\begin{tabular}{|c|c|c|c|}
\hline $\begin{array}{c}\text { Likelihood } \\
\text { Score }\end{array}$ & Likelihood level & Severity Score & Severity level \\
\hline 1 & Rare & 1 & Insignificant \\
\hline 2 & Unlikely & 2 & Mainor \\
\hline 3 & possible & 3 & Moderate \\
\hline 4 & Likely & 4 & Critical \\
\hline 5 & Almost Certain & 5 & Catastrophic \\
\hline
\end{tabular}

Table 3. Risk Matrix

\begin{tabular}{|c|c|c|c|c|c|c|}
\hline \multicolumn{2}{|c|}{ Risk Matrix } & \multicolumn{5}{|c|}{ Severity } \\
\hline & & insignificant & Minor & Moderate & Major & Catastrophic \\
\hline \multicolumn{2}{|r|}{ Score } & 1 & 2 & 3 & 4 & 5 \\
\hline \multirow{5}{*}{$\begin{array}{l}\text { L } \\
\text { i } \\
\text { k } \\
\text { e } \\
\text { li } \\
\text { h } \\
0 \\
0 \\
\text { d }\end{array}$} & $\begin{array}{l}\text { Almost } \\
\text { Certain }\end{array}$ & 5 & 10 & 15 & 20 & 25 \\
\hline & Likely & 4 & 8 & 12 & 16 & 20 \\
\hline & Possible & 3 & 6 & 9 & 12 & 15 \\
\hline & Unlikely & 2 & 4 & 6 & 8 & 10 \\
\hline & Rare & 1 & 2 & 3 & 4 & 5 \\
\hline \multicolumn{3}{|c|}{ Risk Score } & $<6$ & $6-9$ & $10-15$ & $>15$ \\
\hline \multicolumn{3}{|c|}{ Risk Level } & Low & Medium & High & Very high \\
\hline
\end{tabular}

Table 4. Water Security Scoring System

\begin{tabular}{|c|c|c|c|}
\hline Risk Score & Risk Level & Water Security Score & Water Security Level \\
\hline (RS) & (RL) & (WSS) & (WSL) \\
\hline $1 \leq \mathrm{RS}<6$ & Low & 4 & High \\
\hline $6 \leq \mathrm{RS}<10$ & Medium & 3 & Challenging \\
\hline $10 \leq \mathrm{RS}<16$ & High & 2 & Low \\
\hline $\mathrm{RS} \geq \mathbf{1 6}$ & Extreme & $\mathbf{1}$ & Very Low \\
\hline
\end{tabular}

\section{Conclusion}

This paper presented the use of the risk assessment approach for the evaluation of the water security, which constitutes a major issue for a large number of countries. This methodology includes 3 steps: identification of the drivers of the water risk and their associated indicators, determination for each indicator of the scores of its severity and likelihood and finally the evaluation of the risk score according to Eq.1.

The paper presented also the first stage of the application of this methodology on Palestine territory. Literature review and discussion with experts allowed the identification of three categories of drivers: water resources, quality of water services and water 
governance. For each driver, the paper presented the associated indicators. The paper presented also the scales to be used in the risk assessment.

Work is under progress to collect data from some cities in order to conduct water security benchmarking between these cities.

\section{References}

1. United Nations Educational, Scientific and Cultural Organization. WWAP (United Nations World Water Assessment Programme)/UN-Water, 2018. The United Nations World Water Development Report 2018: Nature-Based Solutions for Water. Paris.

2. Jonathan Lautze and Herath Mathrithilake, 2012. Water security: Old concepts, new package, what value?. GWF Discussion Paper 1250, Global Water Forum, Canberra, Australia. Available online at: http://www.globalwaterforum.org/2012/11/20/water-security-oldconcepts-newpackage-what-value/.

3. Maziotis, A., Molinos-Senante, M. and Sala-Garrido, R., 2016. Assessing the impact of quality of service on the productivity of water industry: a MalmquistLuenberger approach for England and Wales.

4. Zeitoun, M., 2011. The Global Web of National Water Security. Global Policy 2(3): 286-296.

5. Organization for Economic Co-operation and Development (OECD), 2013.Water Security for Better Lives, OECD Studies on Water. OECD Publishing. http://dx.doi.org/10.1787/9789264202405-en.

6. World Bank, 2010. The Cost to Developing Countries of Adapting to Climate Change. Washington.

7. Schmeier S., 2013. Governing International Watercourses. The Contribution of River Basin Organizations to the Effective Governance of Internationally Shared Rivers and Lakes. London: Routledge.

8. United Nations University. Institute for Water, Environment \& Health (UNUINWEH), 2013. Water Security \& the Global Water Agenda. Hamilton. Ontario. ISBN 978-92-808-6038-2.

9. Olli Varis , Marko Keskinen and Matti Kummu, 2017. Water \& Development Research Group, Aalto University, Espoo, Finland, " Four dimensions of water security with a case of the indirect role of water in global food security", Water Security 1 (2017) 36-45, Elsevier, 2017.

10. Grey D, Garrick D, Blackmore D, Kelmen J, Muller M, Sadoff C, 2013. Water security in one blue planet: twenty-first century policy challenges for science. Phil. Trans. R. Soc. A 371, 20120406. (doi:10.1098/rsta.2012.0406).

11. Jim Hall and Edoardo Borgomeo, 2013. Risk-based principles for defining and managing water security. Philos Trans A Math Phys Eng Sci. 2013 Nov 13; 371(2002): 2012040. DIO: 10.1098/rsta.2012.0407.

12. Mason N, Calow R., 2012. Water security: from abstract concept to meaningful metrics: an initial overview of options. London, UK: Overseas Development Institute.

13. Dustin Garrick and Jim W. Hall, 2014. Water Security and Society: Risks, Metrics, and Pathways. Annu. Rev. Environ. Resour. 2014. 39:611-39, DOI: 10.1146/annurev-environ-013012-093817. 
14. Water Sector Regulatory Council, 2018. Bridge to Sustainability, Water and Wastewater Service Providers, Performance Monitoring Report for the Year 2016, Ramallah, Palestine.

15. World Bank, 2018. Toward Water Security for Palestinians: Wes Bank and Gaza Water Supply Sanitation, and Hygiene Poverty Diagnostic.

16. Global Water Partnership Mediterranean (GWP-Med.), 2015. Water Governance in Palestine: Sector reform to Include Private Sector Participation (Report developed in the framework Governance and Financing for The Mediterranean Water Sector with support of SWEDEDN Med-Partnership in Partnership with OECD under the guidance of Palestine Water Authority). 